\title{
Characterization of an absorbent based on Raphanus sativus (L. var.), a solid residue from biodiesel production, for the removal of methylene blue
}

\author{
D. A. Lázaro ${ }^{1}$, C. L. Caldeira ${ }^{1}$, M. S. S. Dantas ${ }^{1}$, A. S. Franca ${ }^{2}$ \\ \& M. B. Mansur ${ }^{1}$ \\ ${ }^{1}$ Department of Metallurgical and Materials Engineering, \\ Federal University of Minas Gerais, Brazil \\ ${ }^{2}$ Department of Mechanical Engineering, \\ Federal University of Minas Gerais, Brazil
}

\begin{abstract}
In this study, an adsorbent produced from Raphanus sativus (L. var.), a residue from the biodiesel industry, was investigated for the removal of methylene blue (MB) from textile effluents aiming to: (i) obtain physical and textural characteristics of the given carbon, and (ii) understand the MB adsorption mechanism onto such carbonaceous structures. The following methods were employed: SEM-EDS microscopy, gas adsorption and Raman spectroscopy. Physical and textural characteristics of the carbon obtained by classical methodologies such as BET, BJH and SEM analyses were corroborated by the Raman analysis. For the experimental conditions used on the preparation of the activated carbon of Raphanus sativus, the main physical parameters measured were specific surface area $\left(236.3 \mathrm{~m}^{2} \cdot \mathrm{g}^{-1}\right)$, total pore volume $\left(0.06 \mathrm{~cm}^{3} \cdot \mathrm{g}^{-1}\right)$ and average pore size $(1.4 \mathrm{~nm})$. SEM and Raman analysis revealed that a microporous structure of carbon was obtained as the ratio between the disorder band and the graphite band was higher than unity, thus indicating that MB adsorption may occur predominantly at the surface of the adsorbent, given that the diameter of MB molecule was estimated to be nearly $1.5 \mathrm{~nm}$. Raman analysis of solid MB revealed that MB molecules are predominantly found as dimmers in the solid however they are adsorbed as monomer in the Raphanus sativus carbon. Results evidence that $\mathrm{MB}$ adsorption probably occurs by bonding of monomer
\end{abstract}


MB through the central nitrogen atom of its molecule; MB bonding through sulfur atom may also occur but at lesser intensity while MB bonding through amino nitrogen atom does not seem probable.

Keywords: carbon characterization, Raman spectroscopy, adsorption, methylene blue.

\section{Introduction}

The removal of synthetic dyes from textile wastewaters is extremely important to allow the reuse of water and/or the final discharge of effluent because most of such dyes are toxic, mutagenic and carcinogenic. Several methods have been developed to remove dyes from aqueous solutions in order to decrease their impact on the environment. A comparative survey of technologies including adsorption, coagulation, chemical degradation, ultrafiltration, photodegradation with ozone, electrochemical flotation and biodegradation is found elsewhere [1-6].

As long as there is no universal method available for color removal from aquatic systems, some technologies have been extensively investigated for the remediation of dyes using non-conventional low-cost sorbents based on waste materials generated by industrial and/or agricultural activities such as wheat, corn straw, olive stones, bagasse, birch wood, miscanthus, sunflower shell, pinecone, rapeseed, cotton residues, olive residues, pine rayed, eucalyptus maculata, sugar cane bagasse and many others [7]. Recently the removal of methylene blue (MB) using activated carbons based on the pressed cake of Raphanus sativus (L. var.), which is a residue from the biodiesel industry, was found to be technically feasible [6].

In this context, the aim of this paper is to characterize the activated carbon produced from Raphanus sativus (L. var.) using SEM-EDS (Scanning Electron Microscopy coupled with X-ray Energy Dispersive Spectrometry), gas adsorption and Raman spectroscopy methods in order to better understand the adsorption behavior of $\mathrm{MB}$ from aqueous solutions as well as of other cationic dyes produced by textile industries.

\section{Experimental}

\subsection{Preparation of the carbon from Raphanus sativus (L. var.)}

Activated carbon from Raphanus sativus (L. var.) was prepared according to the following procedure. Firstly, seeds of Raphanus sativus were screw-pressed (Ecirtec, Brazil) for oil extraction followed by Sohxlet extraction procedure at $60^{\circ} \mathrm{C}$ for $6 \mathrm{~h}$ to remove the excess of oil still present in the cake. Samples of the cake were weighted (20 g), placed in ceramic containers and then submitted to one-step thermal activation procedure (carbonization) using an electric muffle furnace. 
During the carbonization, samples were initially burned at $100^{\circ} \mathrm{C}$ for $10 \mathrm{~min}$. Temperature was then raised at the rate of $10^{\circ} \mathrm{C} \mathrm{min}^{-1}$ to $800^{\circ} \mathrm{C} ; \mathrm{N}_{2}$ gas was injected into the furnace $\left(\mathrm{N}_{2}\right.$ flow rate $\left.=0.5 \mathrm{~L} \mathrm{~min}^{-1}\right)$ when $\mathrm{T} \geq 300^{\circ} \mathrm{C}$ in order to create an inert atmosphere. Finally, temperature was maintained constant at $800^{\circ} \mathrm{C}$ for $40 \mathrm{~min}$. After carbonization samples were cooled down and submitted to the characterization tests described as follows. The carbonization procedure was based on preliminary tests and also on literature data for the production of adsorbents using coffee beans pressed cake as precursor material [8].

\subsection{Morphological analysis and determination of textural properties}

Morphological characteristics of the adsorbent surface (before and after carbonization) were carried out by Scanning Electron Microscopy (SEM) using a JEOL microscopy (model JSM6360LV). Due to the non-conductive nature of the material, samples were covered with a thin layer of gold. The qualitative composition at surface of some particles was obtained by SEM coupled with Xray Energy Dispersive Spectrometry (EDS) using a Thermo Noram spectrometer (model Quest).

Surface area, total pore volume and average pore diameter were assessed by measuring multipoint $\mathrm{N}_{2}$ isotherms at $77 \mathrm{~K}$ in an Autosorb-1 MP (Quantachrome). For such analysis, samples were outgassed at $473 \mathrm{~K}$ under vacuum for $3 \mathrm{~h}$. The specific surface area value was calculated according to the Brunauer-Emmett-Teller (BET) equation and pore parameters (pore volume and pore diameter) were evaluated based on Barrett-Joyner-Halenda (BJH) model.

\subsection{Raman spectroscopy analysis}

Raman analysis was carried out in order to evaluate the structural change of the activated carbon due to the adsorption of MB using a Jobin-Yvon/Horiba Raman laser system (model Labran HR800) coupled with a transference optic microscopy. Samples of carbon (unloaded and MB loaded samples) were analyzed under the following conditions: lens 100x, laser power $<1 \mathrm{~mW}$, laser acquisition time $=20 \mathrm{~s}$ (acquisitions $5 \mathrm{x}$ ), red laser wavelength $=632.8 \mathrm{~nm}$, analysis in two points $(1 \mu \mathrm{m})$. MB loaded carbon samples were obtaining by contacting $\mathrm{MB}$ solutions in $250 \mathrm{~mL}$ agitated Erlenmeyer flasks $(100 \mathrm{rpm})$ at following conditions [6]: initial $\mathrm{MB}$ concentration $=500 \mathrm{mg} \mathrm{L}^{-1}$; initial $\mathrm{pH}=5$; adsorbent dosage $=10 \mathrm{~g} \mathrm{~L}^{-1} ; \mathrm{T}=25^{\circ} \mathrm{C} ; \mathrm{t}=72 \mathrm{~h}$. The flasks were covered with aluminium foil to prevent photodegradation. As it was not possible to get the Raman spectra for MB solutions in concentrations as those commonly used in the adsorption tests (an intense fluorescence was obtained probably due to the color of solution), the solid MB reagent was evaluated for comparative analysis under the following conditions: laser power $=0.08 \mathrm{~mW}$ (power was raised to reduce signal noise), wavelength $=632.8 \mathrm{~nm}$, laser acquisition time $=10 \mathrm{~s}$. Analytical MB, 15\% hydrated, (95\% purity, Labsynth, Brazil) was used to load carbon for Raman analysis. 


\section{Results and discussion}

\subsection{Morphological analysis and determination of textural properties}

A typical view of produced adsorbent is shown in Fig. 1(a) (SEM micrographs at resolution of $25 \mathrm{x})$.
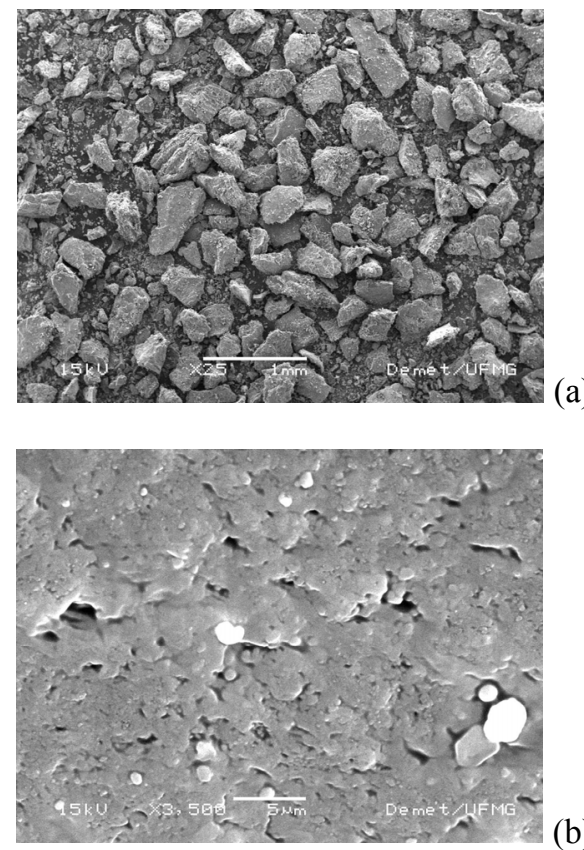

(b)

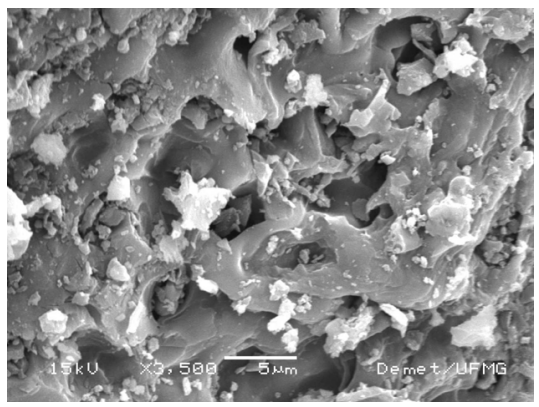

(c)

Figure 1: Typical surface morphology of Raphanus sativus and the produced adsorbent at different SEM micrograph resolutions: (a) Adsorbent at SEM resolution of $25 \mathrm{x}$, (b) Raphanus sativus (raw material) at SEM resolution of 3,500x, and (c) Adsorbent at SEM resolution of $3,500 x$. 
It can be seen that particles of homogeneous color, highly irregular shapes and different sizes were obtained; in fact, particles are smaller than $1 \mathrm{~mm}$ size and they could be classified into fine and coarse fractions due to low mechanical resistance of the material. In addition, particles seem to be not too porous, so adsorption is expected to occur predominantly at the surface of the carbon. Such evidence is corroborated by analyzing SEM micrographs at resolution of 3,500x as shown in Figs. 1(b) and 1(c). As expected, an increase on the porosity of Raphanus sativus due to carbonization was verified but it was not significant for the conditions studied. It might explain why adsorption of MB was found to occur predominantly at the surface of the adsorbent [6].

The qualitative composition given by EDS shown in Fig. 2 reveals that particles contain predominantly carbon, as well as phosphorous, calcium, magnesium and potassium. Metals such as zinc and copper were found at very low quantities while presence of gold in the carbon is due to the thin layer of metal which covered the sample to carry out SEM analysis. The presence of oxygen was found to be quite low as well.

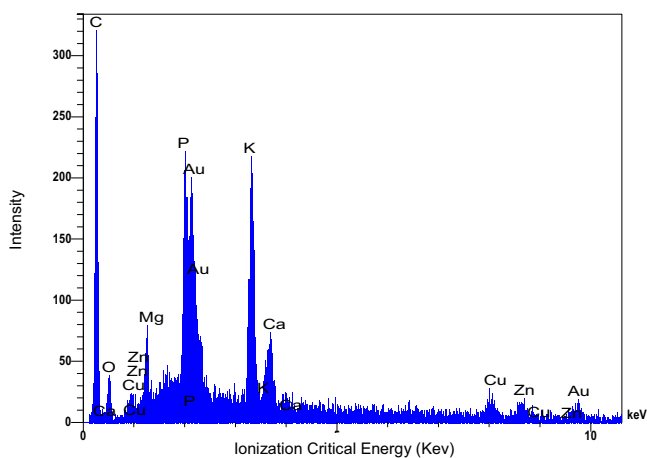

Figure 2: Qualitative composition of the activated carbon surface of Raphanus sativus by EDS analysis.

The following properties of the activated carbon of Raphanus sativus (L. var.) were estimated by $\mathrm{N}_{2}$ gas adsorption: specific surface area $=236.3 \mathrm{~m}^{2} \mathrm{~g}^{-1}$ (Multipoint BET equation, $\left.\mathrm{R}^{2}=0.998\right)$, total pore volume $=0.06 \mathrm{~cm}^{3} \mathrm{~g}^{-1}(\mathrm{BJH}$ method) and average pore size $=1.4 \mathrm{~nm}$ (BJH method). Such results reveal that specific surface area and total pore volume of the produced adsorbent are low if compared to other carbons from agricultural residues. Ioannidou and Zabaniotou [7], for instance, pointed out the surface area of apricot stones activated carbon is $1190 \mathrm{~m}^{2} \mathrm{~g}^{-1}$ (similar to some commercial activated carbons) with total pore volume of $0.5 \mathrm{~cm}^{3} \mathrm{~g}^{-1}$ while the carbon from oat hulls has surface area ranging from 349 to $625 \mathrm{~m}^{2} \mathrm{~g}^{-1}$ with total pore volume from 84.2 to $91.4 \mathrm{~cm}^{3} \mathrm{~g}^{-1}$. Such results, however, do not guarantee satisfactory MB adsorption. Ferrero [9] reported that although hazelnut shells activated carbon achieved high surface area due to thermal treatment $\left(793 \mathrm{~m}^{2} \mathrm{~g}^{-1}\right)$, the maximum adsorption capacity at equilibrium was $\mathrm{q}_{\max }=8.8 \mathrm{mg} \cdot \mathrm{g}^{-1}$, as opposed to 18.3 mg.g ${ }^{-1}$ obtained for the adsorbent based produced in the present study [6]. 
The Langmuir isotherm was also obtained in the BET test $\left(\mathrm{R}^{2}=0.999\right)$ thus giving Langmuir surface area $=366.4 \mathrm{~m}^{2} \cdot \mathrm{g}^{-1}$ and Langmuir constant $\mathrm{K}=98.795$. The adsorption (A) and desorption (D) isotherms for the activated carbon of Raphanus sativus shown in Fig. 3 reveal that an IUPAC type I isotherm was obtained. Such curves are normally encountered when adsorption is limited to at most only a few molecular layers and to microporous carbons whose pore size does not exceed a few adsorbate molecular diameters so, once the micropores are filled there is only a small fraction of the original surface exposed for continued adsorption [10].

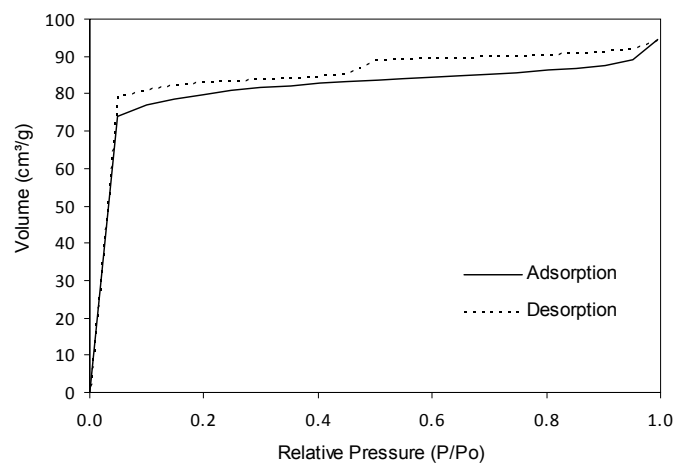

Figure 3: Adsorption (A) and desorption (D) isotherms of Raphanus sativus activated carbon of BET test.

\subsection{Raman spectroscopy analysis}

Raman spectra of the activated carbon of Raphanus sativus before (unloaded carbon) and after MB adsorption (loaded carbon) are shown in Fig. 4. Two characteristic bands which are typical of carbonaceous materials used as precursors for activated carbons were found at 1340 and $1590 \mathrm{~cm}^{-1}$ in the unloaded carbon, thus corresponding to the disorder line (D band) and the graphite line ( $\mathrm{G}$ band), respectively; another characteristic band was identified at $2793 \mathrm{~cm}^{-1}$ but much softer than D and $G$ bands. The intensity of D and $G$ bands is an indicative of the structure of the carbon. In fact, the amount of disorganized carbons which is characterized by the intensity ratio of $D$ to $G$ bands (hereafter named ID/IG ratio) will affect both the pore structure and the adsorption properties of the adsorbent. Haghseresht et al. [11] evaluated the relationship between ID/IG ratio with total BET surface area, total pore volumes, micropore volumes, mesopore volumes and other parameters for a number of microporous carbonaceous adsorbents prepared by oxidation of coal reject in various conditions prior to heat treatment at $600^{\circ} \mathrm{C}$. They verified an increase on the adsorption capacity of the resulting carbons for organic compounds with the increase of ID/IG ratio. Also, higher amount of disorganized carbons (which is related to the increase on the amount of aromatic compounds in comparison with 
aliphatic carbons) indicates lesser space between the clusters of aromatic compounds, hence smaller micropores are obtained. For Raphanus sativus activated carbon shown in Fig. $4, \mathrm{ID} / \mathrm{IG}=1.20$ for the unloaded carbon, thus indicating that pores are probably too small (microporous) and corroborating previous BET observations. Fig. 4 also shows an intense peak in the MB loaded curve at $480 \mathrm{~cm}^{-1}$ as well as other less intense peaks that are related to the adsorption of $\mathrm{MB}$; the interaction between $\mathrm{MB}$ and the carbon of Raphanus sativus is discussed as follows.

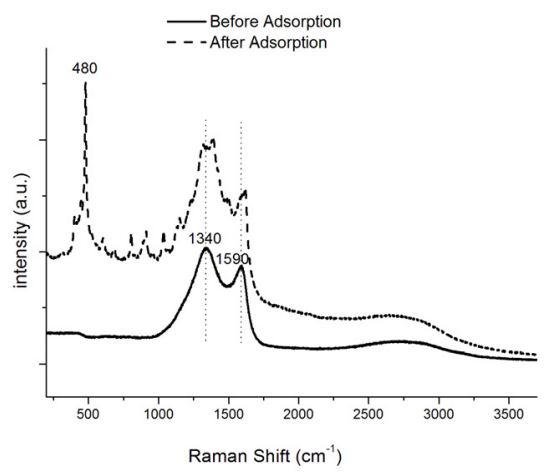

Figure 4: Raman spectra of activated carbon of Raphanus sativus before and after MB adsorption.

In order to evaluate how MB molecules are adsorbed in the Raphanus sativus carbon and also to identify the predominant adsorption mechanism involved in this separation, the MB loaded carbon spectra was subtracted from the unloaded carbon spectra; a comparison between this curve and that of solid MB spectra is shown in Fig. 5(a) as the Raman spectra of MB aqueous solutions was not possible to be carried out. In fact, the bonding between MB and carbon can be identified according to changes verified in the peak positions of both curves. In order to obtain a better visualization of the Raman spectra, the curves shown in Fig. 5(a) were split into regions according to Raman shift interval of 200 to 700 $\mathrm{cm}^{-1}$ and 700 to $1700 \mathrm{~cm}^{-1}$, shown respectively in Fig. 5(b) and 5(c).

According to Rubim et al. [12], the bands identified at 448,480 and $500 \mathrm{~cm}^{-1}$ as shown in Fig. 5(b) are associated to the aggregation state of the MB molecules that might change due to the contact with the carbon surface or even with $\mathrm{pH}$ of the aqueous solution. The presence of dimmer-MB species is evidenced by peaks around 448 and $500 \mathrm{~cm}^{-1}$ while the monomer-MB species can be identified at $485 \mathrm{~cm}^{-1}$ ( $\delta$ (CNC) skeletal deformation mode). Therefore, according to Fig. 5(b), MB molecules are predominantly found as dimmers in the solid but they are adsorbed as monomer in the Raphanus sativus carbon. Recently, UV-vis analysis of aqueous solutions containing MB carried out by Tafulo et al. [13] pointed to the non existence of dimmers in the aqueous solution as referred by 

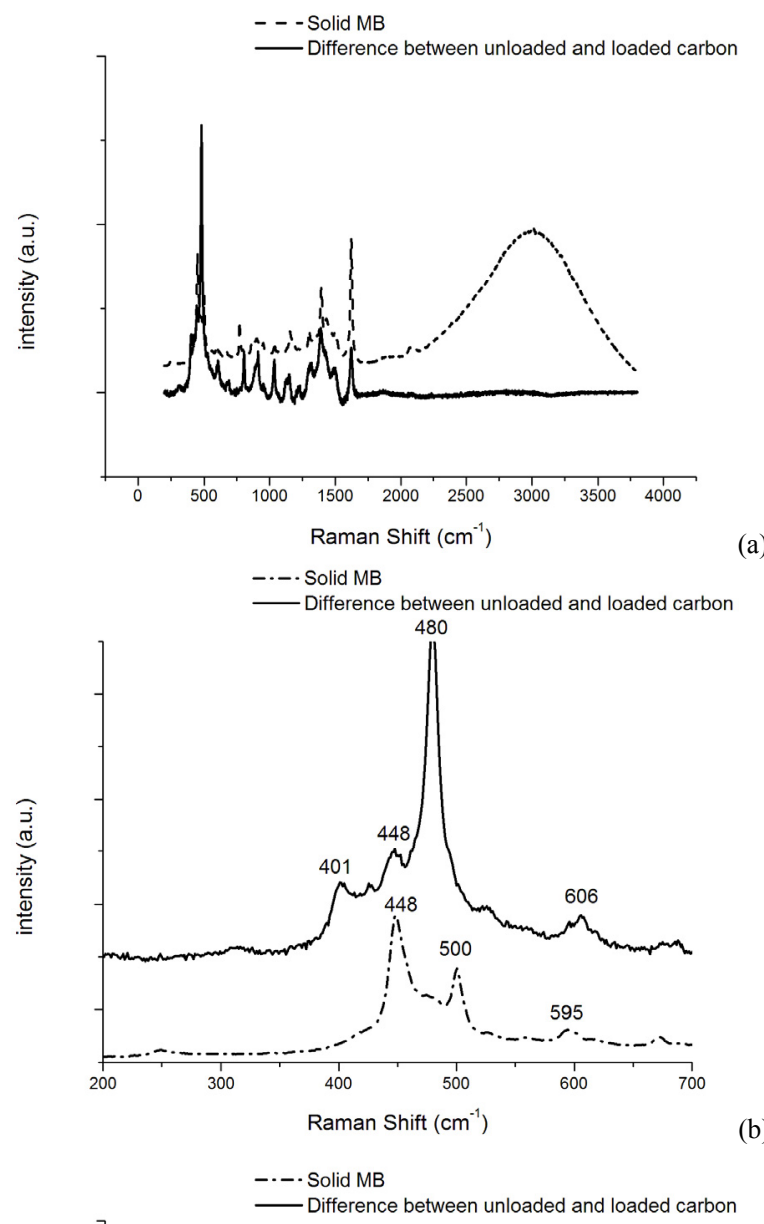

(a)

(b)

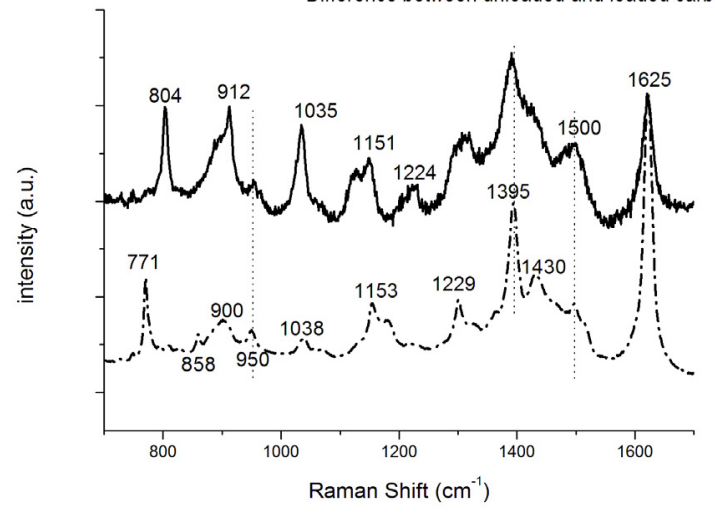

(c)

Figure 5: Raman spectra of solid $\mathrm{MB}$ and the spectra difference between unloaded and MB loaded carbon: (a) 0 to $4000 \mathrm{~cm}^{-1}$, (b) 200 to 700 $\mathrm{cm}^{-1}$ and (c) 700 to $1700 \mathrm{~cm}^{-1}$. 
several authors and that changes on the position and shape of bands obtained by them are in fact influenced by the ionic strength of the solution. The chemical structure of $\mathrm{MB}$ and its possible dimerization reaction in solution is shown in Fig. 6. The peak at $401 \mathrm{~cm}^{-1}$ can be attributed to some deformation in the C-S-C bond of the MB species [14] and no significant change in the intensity of peaks nearby $600 \mathrm{~cm}^{-1}$ was considered.

Some peaks related to atoms deformation in the molecules of solid $\mathrm{MB}$ and adsorbed $\mathrm{MB}$ are shown in Fig. 5(c). Firstly, peaks related to the $\mathrm{CH}$ bond deformation $\beta(\mathrm{C}-\mathrm{H})$ are found at 1030 and $1151 \mathrm{~cm}^{-1}$ [15]. One peak was identified at $1038 \mathrm{~cm}^{-1}$, showing low intensity in the solid MB spectra but being quite significant when $\mathrm{MB}$ molecules are adsorbed in the Raphanus sativus carbon; the other peak occurred at $1153 \mathrm{~cm}^{-1}$ for both curves with quite similar intensities. Other deformation on the atoms of $\mathrm{MB}$ molecules is related to the symmetric and asymmetric stretch of C-N bond that are found at 1390 and 1430 $\mathrm{cm}^{-1}$, respectively [15]. According to Fig. 5(c), the symmetric stretch of C-N bond occurs in both solid and MB loaded carbon, but the asymmetric stretch of $\mathrm{C}-\mathrm{N}$ bond has been identified in the solid only. And finally a typical large MB peak was found at $1625 \mathrm{~cm}^{-1}$ for both spectra which is related to the $\mathrm{C}-\mathrm{C}$ bond stretch of the benzene ring of MB molecule [15-16]. It was considerably more intense in the solid MB spectra. Other non identified peaks occurred at 771, 858, 900,950 and $1229 \mathrm{~cm}^{-1}$ for the solid MB spectra and at 804, 912, 1224 and 1500 $\mathrm{cm}^{-1}$ for the MB adsorbed in the carbon.

The identification of bands that have appeared, disappeared or just shifted after adsorption of $\mathrm{MB}$ molecules in comparison with those bands of solid $\mathrm{MB}$ may help to elucidate how MB can possibly be linked to the adsorbent based on Raphanus sativus. Hutchinson and Hester [16], studying the structure of the surface coat of a thionine-modified gold electrode, suggested that the coat occurred basically by thionine units linked via an amino nitrogen in a secondary amine structure. According to the molecule of MB shown in Fig. 6, there are three probable sites for this bonding: the central nitrogen atom, the central sulfur atom and/or the amino nitrogen atoms. MB bonding as monomer species through

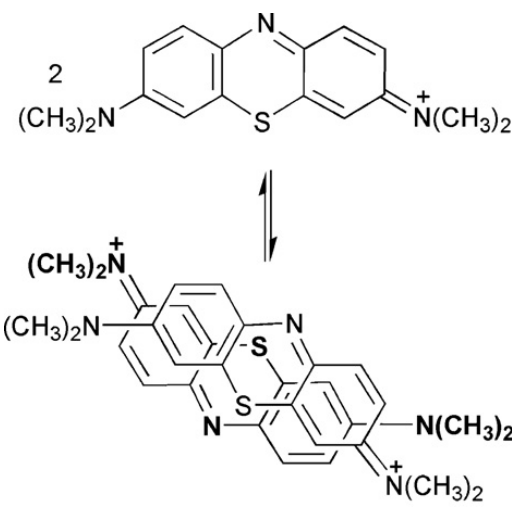

Figure 6: $\quad$ MB chemical structure and its possible dimmer [13]. 
the central nitrogen atom seems to be the most probable mechanism to occur during adsorption of $\mathrm{MB}$ molecules onto Raphanus sativus carbon because a very high intensity peak at $480 \mathrm{~cm}^{-1}$ was identified, which is assigned to a $\delta$ (CNC) skeletal deformation mode. MB bonding through the sulfur atom seems to occur as well but at lesser amount because intensity of peak near $405 \mathrm{~cm}^{-1}$, attributed to some deformation in the C-S-C bond of the MB species, has also appeared. However, bonding through an amino nitrogen atom to a carbon atom seems less probable because symmetric stretch of C-N bond $1395 \mathrm{~cm}^{-1}$ was found to be not affected and the asymmetric stretch at $1430 \mathrm{~cm}^{-1}$ just vanished at the MB loaded curve.

\section{Conclusions}

The characterization of carbons is an important step for the design of adsorption processes. Main results on the characterization of the adsorbent based on Raphanus sativus in correlation to MB adsorption are:

- A microporous structure was verified qualitatively (SEM and Raman analysis) indicating that $\mathrm{MB}$ adsorption occurs predominantly at the surface of the adsorbent (surface area $=236.3 \mathrm{~m}^{2} \cdot \mathrm{g}^{-1}$, pore volume $=$ $0.06 \mathrm{~cm}^{3} . \mathrm{g}^{-1}$; pore size $=1.4 \mathrm{~nm}$; MB diameter $\left.\approx 1.5 \mathrm{~nm}[17]\right)$.

- Adsorption probably occurs by MB bonding of monomer species through central nitrogen atom; MB bonding through sulfur atom may occur while MB bonding through amino nitrogen atom seems improbable.

\section{Acknowledgements}

Authors are grateful to the National Institute of Science and Technology (INCT, Brazil): Mineral Resources, Water and Biodiversity for the financial support (MCT/CNPq/FNDCT/CAPES/FAPEMIG/FAPERJ/FAPESP).

\section{References}

[1] I.M. Banat, P. Nigam, D. Singh, R. Marchant, Microbial decolorization of textile-dye-containing effluents: A review, Bioresource Technol. 58 (1996) 217-227.

[2] Y.M. Slokar, M.A. Le Marechal, Methods of decoloration of textile wastewaters, Dyes Pigments 37 (1998) 335-356.

[3] T. Robinson, G. Mcmullan, R. Marchant, P. Nigam, Remediation of dyes in textile effluent: a critical review on current treatment technologies with a proposed alternative, Bioresource Technol. 77 (2001) 247-255.

[4] G. Crini, Non-conventional low-cost adsorbents for dye removal: a review, Bioresource Technol. 97 (2006) 1061-1085. 
[5] A.B. Santos, F.J. Cervantes, J.B. van Lier, Review paper on current technologies for decolourisation of textile wastewaters: Perspectives for anaerobic biotechnology. Bioresource Technol. 98 (2007) 2369-2385.

[6] D.A. Lázaro, M.B. Mansur, A.S. Franca, L.S. Oliveira, S.D.F. Rocha, Performance of cold-pressed cake from Raphanus sativus (L. Var.) oilseeds, a solid residue from biodiesel production, as adsorbent for basic dyes, Int. J. Chem. Eng. 1 (2008) 147-160.

[7] O. Ioannidou, A. Zabaniotou, Agricultural residues as precursors for activated carbon production - A review, Renew. Sust. Energ. Rev. 11 (2007) 1966-2005.

[8] A. Nunes, A.S. Franca, L.S., Oliveira, Activated carbons from waste biomass: An alternative use for biodiesel production solid residues, Bioresource Technol. 100 (2009) 1786-1792.

[9] F. Ferrero, Dye removal by low cost adsorbents: Hazelnut shells in comparison with wood sawdust, J. Hazard. Mater. 142 (2007) 144-152.

[10] S. Lowell, J.E. Shields, Powder surface analysis area and porosity, third ed, Chapman \& Hall, Great Britain, 1991.

[11] F. Haghseresht, G.Q. Lu, A.K. Whittaker, Carbon structure and porosity of carbonaceous adsorbents in relation to their adsorption properties, Carbon 37 (1999) 1491-1497.

[12] J.C. Rubim, M.H. Sousa, J.C.O. Silva, F.A. Tourinho, Raman spectroscopy as a powerful technique in the characterization of ferrofluids, Braz. J. Physics 31 (2001) 402-408.

[13] P.A.R. Tafulo, R.B. Queirós, G. González-Aguilar, On the "concentrationdriven" methylene blue dimerization. Spectrochim, Acta Part A 73 (2009) 295-300.

[14] G.N. Tognalli, A. Fainstai, C. Vericat, M.R. Vela, R.C. Salvarezza, An exploring three-dimensional nanosystems with Raman spectroscopy: methylene blue adsorbed on thiol and sulfur monolayers on gold, J. Phys. Chem. B 110 (2006) 354-360.

[15] R.R. Naujok, V.D. Robert, R.M. Corn, Fluorescence and Fourier transform surface-enhanced raman scattering measurements of methylene blue adsorbed onto a sulfur-modified gold electrode, Langmuir 9 (1993) 17711774.

[16] K. Hutchinson, R.E. Hester, Raman spectroscopic studies of a thioninemodified electrode, J. Chem. Soc., Faraday Trans. I 80 (1984) 2053-2071.

[17] Y. Xun, Z. Shu-Ping, X. Wei, C. Hong-You, D. Xiao-Dong, L. Xin-Mei, Y. $\mathrm{Zi}-\mathrm{Feng}$, Aqueous dye adsorption on ordered mesoporous carbons, J. Colloid and Int. Sci. 310 (2007) 83-89. 